\title{
Principais Fatores de Risco para a Manutenção do Aleitamento Materno Exclusivo no Brasil e EUA
}

\author{
Leticia A. Santiago, ${ }^{1}$ Sérgio Augusto Yukio Hissayassu, ${ }^{2}$ Paula Moura Del Comuni ${ }^{3}$
}

\begin{abstract}
RESUMO
O objetivo do presente estudo foi identificar, por meio de revisão bibliográfica nacional e internacional, os principais fatores responsáveis pelo Desmame Materno Precoce (DMP) no Brasil e nos Estados Unidos da América (EUA) e estabelecer uma análise comparativa entre ambos. Caracteriza-se por ser um estudo descritivo, baseado em revisão de literatura, a partir de artigos citáveis nos idiomas Português e Inglês, disponíveis nas bases de dados Scientific Electronic Library Online (SciELO) e Public Medline (PubMed), publicados entre os anos de 2003 e 2017, na área temática Ciências da Saúde. Na PubMed utilizou-se o descritor Exclusive breastfeeding, sendo encontrados 60 artigos. Já na SciELO, com a junção dos descritores Aleitamento Materno e Desmame, encontrou-se 49 trabalhos. Observou-se que o retorno da mãe ao mercado de trabalho foi um dos principais fatores de risco para o DMP em ambos os países. No Brasil, contudo, o amparo legal oferecido pela licença-maternidade refletiu em $41 \%$ de Aleitamento Materno Exclusivo (AME) até os seis meses, enquanto nos EUA a ausência desse direito conferiu média nacional de apenas $8 \%$ para o AME. O estudo demonstrou que o amparo legislativo tem impacto positivo na adesão das mães ao AME ao colaborar na interação entre o binômio mãe-filho, estimulando a prática da amamentação.
\end{abstract}

Palavras-chave: Exclusive breastfeeding. Aleitamento materno. Desmame.

\section{MAIN OBSTACLES FOR THE MAINTENANCE OF EXCLUSIVE BREASTFEEDING IN THE BRAZIL AND US COUNTRIES}

\section{ABSTRACT}

Identify, through a national and international bibliographic review, the main factors that corroborate with the Early Maternal Weaning (WMD) in Brazil and the United States of America, and to establish a comparative analysis of these countries. Descriptive study, based on a review of the literature, from Portuguese and English, available in the Scientific Electronic Library Online (SciELO) and Public Medline (PubMed) databases, published between 2003 and 2017, in the thematic area Sciences of Health. In PubMed, the descriptor Exclusive breastfeeding was used, being found 60 manuscripts. In SciELO, with the combination of the descriptors Breastfeeding and Weaning, it was observed 49 studies. It was observed that the mother's return to the labor market was one of the main risk factors for WMD in both countries. However, in Brazil the legal support offered by maternity leave reflected in $41 \%$ of Exclusive Breastfeeding (EB) until six months, while in the US, the absence of this right led to a national average of only $8 \%$ for the WMD. The study showed that legislative support has a positive impact on the mother's adherence to EB by collaborating in the interaction between the mother-child binomial, stimulating the practice of breastfeeding.

Keywords: Exclusive breastfeeding. Breastfeeding. Weaning.

\footnotetext{
Docente do Departamento de Medicina na Graduação em Medicina e Residência em Medicina de Família e Comunidade da Universidade de Taubaté. Mestre em Desenvolvimento humano: Formação, Políticas e Práticas sociais pela Universidade de Taubaté. le.santiago@yahoo.com.br

2 Graduado em Medicina pela Universidade de Taubaté (Unitau) em 2017.

${ }^{3}$ Médica formada pela Universidade de Taubaté em 2019. pmdc114@gmail.com
} 


\section{INTRODUÇÃO}

O aleitamento materno nos primeiros anos de vida é comprovadamente benéfico, tanto para a mãe quanto para a criança, pois oferece vantagens nutricionais, imunológicas e psicológicas ao recém-nascido (RN). Além disso, estreita os vínculos entre a mãe e o bebê (TOMA; REA, 2008).

A Organização Mundial da Saúde (OMS) ressalta que a prática da amamentação salva a vida de 6 milhões de crianças a cada ano, prevenindo doenças diarreicas e infecções respiratórias agudas (WORLD..., 2012).

Entre os principais benefícios do aleitamento materno para a mulher encontram-se a aceleração da recuperação do parto por ação da ocitocina na involução uterina, redução da resposta ao estresse materno e perda de peso após gravidez (BRASIL, 2015a).

Ainda, para a família os benefícios guardam relação com economia em: alimentação consultas médicas, medicamentos, exames laboratoriais e hospitalização do bebê. Para a criança, o aleitamento materno está relacionado à diminuição do risco de alergias, hipertensão arterial, dislipidemias e diabetes. Evita mortes infantis, doenças diarreicas e respiratórias, reduz a chance de obesidade, melhora a nutrição, promove efeito positivo na inteligência e o desenvolvimento da cavidade bucal (BRASIL, 2015a).

Corrobora essa afirmação o estudo de Victora et al. (2015) intitulado "Associação entre aleitamento materno e inteligência, escolaridade e renda aos 30 anos: estudo prospectivo de coorte de nascimentos no Brasil", no qual os resultados sugerem que a amamentação não só melhora a inteligência até a idade adulta, como também tem um efeito tanto no nível individual quanto no social, aumentando o nível educacional e a capacidade de ganho.

O AME é a oferta apenas de leite materno à criança, diretamente da mama ou ordenhado, ou leite humano de outra fonte, sem outros líquidos ou sólidos, com exceção de gotas ou xaropes contendo vitaminas, sais de reidratação oral, suplementos minerais ou medicamentos (WHO, 2009).

O Desmame Materno Precoce (DMP) é a interrupção do $A M E$ antes dos seis meses de idade. Isso ocorre quando são introduzidas outras formas de alimentos, tanto líquidos quanto sólidos, como chá, água, fórmulas, entre outros (OLIVEIRA et al., 2015).

A interrupção precoce da amamentação ainda é uma realidade em vários países, inclusive no Brasil, o que contradiz as recomendações da OMS e da Fun- dação das Nações Unidas para a Infância (Unicef): que o aleitamento materno deve ser exclusivo até os seis meses de idade e complementar até os dois anos ou mais (BRASIL, 2015a).

Apesar das ações integradas de órgãos como Unicef, Ministério da Saúde (MS), Secretarias de Saúde Estaduais e Municipais, Rede Brasileira de Bancos de Leite Humano e Hospitais Amigos da Criança, de Sociedades de Classe (Medicina, Enfermagem, Nutrição, entre outras), de Organizações Não Governamentais (ONGs) e da Pastoral da Criança do Brasil, que priorizam a promoção, proteção e apoio ao aleitamento natural, a fim de reduzir a mortalidade infantil e melhorar a saúde das crianças, ainda é baixo o número de mulheres que realizam o AME até os seis meses (BRASIL, 2015a).

No Brasil, a Pesquisa Nacional de Demografia e Saúde da Criança e da Mulher apontou prevalência de AME de 23,4 dias, em 1999, e de 54,1 dias, em 2008. Tal resultado ainda está muito aquém da meta preconizada pela OMS, que é de 180 dias (BRASIL, 2015a).

Encontra-se, no entanto, além dos índices de AME nos EUA, em que menos da metade $(43 \%)$ das mães americanas amamentam exclusivamente durante seis meses. O Estado do Mississippi apresenta o pior índice (52,5\%), segundo pesquisadores do Centro de Controle e Prevenção de Doenças (KEDROWSKI; LIPSCOMB, 2008).

A própria OMS revelou uma pesquisa em nível mundial, segundo a qual apenas $38 \%$ das crianças são amamentadas exclusivamente com leite materno nos seis primeiros meses de vida, embora a meta fosse elevar a taxa mundial em pelo menos 50\% até 2015.

Fato interessante refere-se ao papel da Pastoral da Criança na manutenção do $\mathrm{AME}$, pois os dados do primeiro trimestre de 2014 demonstraram que 70,1\% das crianças acompanhadas mamam exclusivamente no peito até os seis meses. É importante destacar que esse serviço de promoção ao aleitamento materno é realizado com o auxílio de voluntários (PASTORAL..., 2017).

A doação de leite humano é uma iniciativa que também promove o AME. O Brasil destaca-se por ter a maior, mais complexa e gratuita rede de bancos de leite do mundo, com 221 unidades e 186 postos de coleta, suprindo $60 \%$ da demanda para os RNs prematuros e de baixo peso internados em Unidades de Terapia Intensiva Neonatais do país (BRASIL, 2015a).

Por outro lado, nos EUA, além do leite humano ser comercializado com fins lucrativos, prática proibida no Brasil, há apenas 23 bancos de leite humano em 
21 Estados americanos e outros três bancos credenciados em território canadense (GRAZZIOTIN; CARVALHO, 2017), o que também favorece o DMP no país.

A etiologia do DMP é multifatorial, incluindo intercorrências no puerpério, insegurança por parte da mãe, falta de orientação e de apoio da família e do companheiro, ausência de assistência e de orientações pelos profissionais da saúde durante o pré-natal, introdução de fórmulas artificiais, bicos e mamadeiras, necessidade de retorno da mãe ao trabalho, crenças como a de que a mãe acha que possui pouco leite e que este não supre a fome do bebê, conflitos com a autoimagem, entre outras (CYRILLO et al., 2009).

Outros fatores, como a idade materna, nível de escolaridade, tipo de parto, profissão da mãe e peso do RN também têm sido apontados como possíveis causas de DMP (ROCCl; FERNANDES, 2014).

Algumas ações, como a adoção do sistema de alojamento conjunto, alterações na legislação trabaIhista, objetivando amparar a gestante e a lactante, a melhoria dos programas de atendimento à gestante e à criança, a criação dos bancos de leite humano, o método canguru, a norma brasileira de comercialização de alimentos para lactentes, a formação de profissionais para atuarem na atenção primária de saúde, culminando com a iniciativa Hospital Amigo da Criança, entre outras, contribuíram para que o aleitamento materno voltasse a desempenhar seu papel de protagonismo, proporcionando benefícios diretos e indiretos ao binômio (ROCCI; FERNANDES, 2014; CYRILLO et al., 2009).

Este estudo objetivou identificar, por meio de revisão bibliográfica nacional e internacional, os principais fatores responsáveis pelo DMP no Brasil e nos Estados Unidos da América (EUA) e estabelecer uma análise comparativa entre ambos os países.

O interesse pela análise comparativa dos principais fatores de risco para a manutenção do AME no Brasil e EUA deu-se a partir das discussões durante Graduação em Medicina, na disciplina de Saúde Coletiva, quando foram abordadas políticas e programas de aleitamento materno como formas de promoção da saúde e prevenção de doenças, conforme preconizam os princípios e diretrizes do Sistema Único de Saúde (SUS).

Por meio dos debates gerados durante as aulas, após leitura de artigos científicos a respeito da temática, evidenciou-se o destaque conferido ao Brasil na elaboração de tais políticas públicas de saúde, como promulgação de leis trabalhistas que amparam a gestante e a nutriz, além da criação da Norma Brasilei- ra de Comercialização de Alimentos para Lactentes e Crianças na Primeira Infância; introdução do Método Canguru; incentivo ao alojamento conjunto; estímulo à educação em saúde na Atenção Primária à Saúde (APS); ampliação dos bancos de leite e de coletas humanos - totalmente gratuitos; investimento em campanhas de promoção ao aleitamento materno; Hospitais e Unidades Básicas de Saúde Amigos da Criança; participação ativa da Pastoral da Criança; Estratégia Amamenta e Alimenta, entre outros.

Este fato é pouco evidenciado nos EUA, país que se posicionou contra a resolução da Organização das Nações Unidas (ONU) que incentiva a amamentação, ameaçando impor sanções comerciais a países que apresentaram texto pró-aleitamento (AGÊNCIA BRASIL, 2018).

Assim, diante das vantagens e benefícios atribuídos ao aleitamento materno, questiona-se quanto aos principais fatores responsáveis pelo DMP no Brasil e nos EUA e procede-se a uma análise comparativa sobre as ações adotadas nesses países.

\section{MÉTODO}

Trata-se de uma pesquisa de caráter bibliográfico, descritivo-exploratória, realizada entre os meses de fevereiro e outubro de 2017, com base em artigos científicos que estivessem gratuitamente disponíveis na íntegra. Foram utilizados os artigos internacionais da base de dados da Public Medline (Pubmed) publicados no período 2003-2017, utilizando-se o descritor: "Exclusive breastfeeding". Das 60 publicações encontradas e analisadas, 49 atendiam aos objetivos propostos. No mesmo recorte temporal, buscou-se também os artigos nacionais publicados na Scientific Electronic Library Online (SciELO), usando-se de forma associada os descritores: "Aleitamento Materno" e "Desmame". As 49 publicações encontradas e analisadas por meio de leitura dos títulos e resumos resultaram em 39 trabalhos.

Os descritores foram selecionados de acordo com a base de dados, em que se optou por utilizar os descritores no idioma Inglês para as pesquisas em Pubmed por reunir somente artigos nessa língua e na SciELO a busca estabeleceu-se por descritores em Português por apresentar boa correspondência de artigos. Para tanto, foi avaliada a validação dos termos na base de Descritores em Ciência da Saúde.

O recorte temporal adotado justifica-se devido ao pequeno número de trabalhos que abordem a temática nos EUA. 
Os artigos selecionados foram analisados comparativamente em relação a sete fatores mais contemplados: abandono do AME por retorno da mãe ao trabalho; estado civil; intercorrências mamárias; prematuridade e baixo peso ao nascer; conhecimento e prática materna; valores culturais e pessoais e influência de profissionais de saúde, familiares e governo.

Para análise dos dados extraíram-se informações que permitiram caracterizar os locais onde os artigos foram desenvolvidos (Brasil e EUA) e os dados relativos aos fatores de risco para o Desmame Materno Precoce (DMP). Posteriormente, essas informações foram analisadas e procedeu-se à comparação entre os dados referentes aos dois países envolvidos no estudo.

\section{RESULTADOS}

Os dois fatores mais discutidos relacionados ao DMP foram o retorno da mãe ao mercado de trabaIho e as influências externas efetuadas por familiares, profissionais da saúde e governo.

Já os menos prevalentes foram o estado civil, presente somente nos artigos brasileiros, no qual o DMP teve maior incidência entre as mães solteiras, justificado pela ausência de apoio do companheiro. Esses dados corroboram os aqueles obtidos por Margotti e Margotti (2017), cujos estudos revelaram que o apoio do companheiro na amamentação tem relação estatisticamente positiva com a manutenção e duração do aleitamento materno. Seguiram-se os fatores conhecimento e prática materna, valores culturais e pessoais e intercorrências mamárias.

O retorno da mãe ao trabalho é um dos fatores que mais influenciam o DMP (FIGUEIREDO, 2009). Nesse aspecto, o Brasil destaca-se internacionalmente como um dos países que oferecem maior tempo de licença-maternidade remunerada (quatro meses, com incentivo governamental às empresas que estenderam esse prazo para seis meses) e percentual de salário pago às mulheres. Ocupa, nesse aspecto, o sétimo lugar, num ranking de 202 países pesquisados pelas Nações Unidas (UNITED NATIONS, 2010).

Entre 1960 e 2009 houve aumento dessa participação de $32 \%$ para $46 \%$, nos EUA, de $25 \%$ para $47 \%$, no Canadá e de $21 \%$ para $41 \%$, na América Latina e no Caribe (WORLD BANK, 2012).

No Brasil, em 1996, aproximadamente $21 \%$ dos lares brasileiros tinham como chefe uma mulher e, em $2012,37,4 \%$ das famílias tinham como pessoa de referência uma mulher (IBGE, 2011).
Dessa forma, orientações sobre o armazenamento do leite são de grande importância, para que se possa diminuir o impacto que o retorno da mãe ao trabalho acarreta ao aleitamento, pois assegura à mãe, além do conhecimento necessário para manter adequadamente o leite, a possibilidade de não interromper a amamentação (ROCCl; FERNANDES, 2014).

Estudo realizado por Rocci e Fernandes (2014) revelou que $11,7 \%$ das mães referiram ter abandonado o AME devido às informações recebidas pelo pediatra, que indicou a complementação do leite materno com fórmulas industrializadas.

Em relação à influência do governo no incentivo ao aleitamento materno, observou-se que as famílias americanas que receberam suporte de suplemento nutricional tiveram uma tendência menor a iniciar a amamentação $(63,2 \%)$ do que as que não o recebiam (86\%), assim como a manter a prática $(26,4 \%)$, em relação às que não a receberam (55,8\%) (LI et al., 2003).

Outro ponto de destaque é o apelo da mídia e de alguns profissionais da saúde em relação á alimentos infantis, leites, mamadeiras e bicos, uma prática considerada ilegal e antiética (REDE..., 2008).

$O$ conhecimento sobre o aleitamento e a experiência em relação à amamentação são fatores que também interferem no AME. De acordo com os artigos brasileiros, a falta de conhecimentos básicos para o cuidado com a criança torna a mãe mais suscetível a tabus e mitos culturais, o que a deixa mais vulnerável ao DMP (JOCA et al., 2005).

Estudos desenvolvidos nos EUA apontaram que o vínculo estabelecido durante o aleitamento estimula as mães a amamentações posteriores. Observou-se, contudo, que a crença errônea de que o leite materno não é suficiente para sustentar o filho até os seis meses de idade ainda é marcante, tratando-se de um fator cultural, um mito, pois a maioria das mulheres tem leite suficiente (ROCCl; FERNANDES, 2014).

Norte-americanas e brasileiras relataram sentimento de insegurança quanto à qualidade nutricional e calórica do leite ofertado ao seu bebê, referindo ter medo de o "leite ser fraco". (Ll et al., 2003).

Dos artigos selecionados, 57,1\% relatam que as mães sentem cobrança social para amamentar, mesmo que $o$ ato the acarrete sofrimentos físicos ou emocionais. Assim, o apoio dos profissionais da saúde contribui para que as nutrizes consigam vencer alguns desafios emocionais (JOCA et al., 2005).

Ao abordar os fatores referentes aos valores pessoais e culturais das nutrizes que interferiram no DMP, $42,85 \%$ dos estudos destacaram que eles têm 
potencial de influenciar a prática da amamentação, pois demonstraram ser o aleitamento materno uma prática que necessita ser aprendida, não constituindo uma atividade instintiva. Tal fato chama a atenção para a importância das orientações durante o pré-natal que podem ser obtidas nas consultas ou nos grupos de apoio (JOCA et al., 2005).

Tais estudos corroboram os trabalhos de Johnston e Esposito (2007), que ressaltam a importância dos fatores subjetivos, sensoriais e afetivos, conscientes e inconscientes na relação estabelecida precocemente entre mãe e filho, que pode ser iniciada no pré-natal. Os autores ainda destacam que o conforto pessoal ao amamentar foi significativo para o prolongamento do aleitamento em até dez semanas, comparativamente às que sentiam vergonha ou insegurança.

Outra questão polêmica relacionada a questões culturais e de valoração, que ainda divide opiniões nos dois países, é sobre o direito das mães de amamentarem seus filhos em locais públicos. No Brasil não há leis que proíbam tal prática, pelo contrário, alguns municípios e Estados aprovaram leis que proíbem que as nutrizes sejam constrangidas ao amamentarem seus filhos em público. Como exemplo, a lei municipal 16.161 de 2015, da cidade de São Paulo, que garante às mães o direito de amamentar em qualquer local da capital paulista (CÂMARA..., 2015).

Problemas mamários foram apontados como desencadeadores da introdução de substitutos do leite materno, devido ao fato de causarem dor à nutriz. A presença de mastites, fissuras, rachaduras ou ingurgitamento mamário podem gerar na mãe apreensão ou medo (MONTESCHIO; GAIVA; MOREIRA, 2015). Como revelado neste estudo, $42,85 \%$ dos artigos apontaram as intercorrências mamárias como possíveis causas de DMP.

\section{DISCUSSÃO}

Quando realizada a comparação entre os dois países, constatou-se que, entre os principais fatores de risco para o DMP, o retorno da mãe ao mercado de trabalho foi o mais prevalente (JONHSTON; ESPOSITO, 2007; KOGAN et al., 2008; KRONENFELD, 2017; LI et al., 2003).

Apesar do resultado obtido, entretanto, observa-se que no Brasil há leis trabalhistas que amparam a gestante, a mãe e a nutriz, no sentido de garantir licença-maternidade de 120 dias consecutivos, sem prejuízo do emprego e da remuneração, podendo ter início no primeiro dia do nono mês de gestação, salvo antecipação médica. Também é vedada a dispensa arbitrária ou sem justa causa da mulher trabalhadora durante o período de gestação e lactação, desde a confirmação da gravidez até cinco meses após o parto (BRASIL, 1988).

A lei ainda preconiza que, para amamentar seu filho, até que ele complete seis meses de idade, a muIher terá direito, durante a jornada de trabalho, a dois descansos, de meia hora cada, e quando assim exigir a saúde do filho.

Além disso, em 2008 entrou em vigor a Lei Federal $n^{\circ} 11.770$, que institui o Programa Empresa Cidadã, que visa a prorrogar para 180 dias a licença-maternidade prevista na Constituição, mediante incentivo fiscal às empresas (BRASIL, 2008).

Nos EUA, apesar da existência de algumas leis, como a "Pregnancy Discrimination Act", vigente desde 1978, que proíbe demissão ou destituição de cargo de funcionária gestante, ou a "Family and Medical Leave" (FMLA), de 1993, que garante aos pais licença não remunerada de 12 semanas para o cuidado com os filhos, lei esta que só vale para empresas com no mínimo 50 funcionários e apenas se o empregado estiver trabalhando no mínimo há um ano na instituição (UNITED STATES, 2014), o governo federal norte-americano não obriga a concessão de licença-maternidade remunerada.

Na Califórnia, por exemplo, existe o programa "Paid Family Leave", que garante à nutriz o pagamento da licença-maternidade por até seis semanas, sendo pago apenas $55 \%$ do salário integral durante essa licença (CALIFORNIA, 2017). Logo, pode-se observar que as mulheres norte-americanas encontram-se em situação de vulnerabilidade quando comparadas às brasileiras, por não terem um respaldo legal único, o que dificulta o fortalecimento do vínculo materno.

Em 2015 o Brasil sancionou o decreto no 8.552, que regulamentou a Lei no 11.265 , de 3 de janeiro de 2006, normatizando a comercialização de alimentos para lactentes e crianças de primeira infância, e também a de produtos de puericultura, como mamadeiras, bicos e chupetas. O objetivo foi assegurar o uso apropriado desses produtos de forma que não haja interferência na prática do aleitamento materno, e auxiliar no controle da publicidade indiscriminada dos alimentos e produtos de puericultura que concorrem com a amamentação (BRASIL, 2015b).

Esse decreto também estabeleceu que houvesse rigor maior na distribuição de amostras gratuitas de fórmulas infantis e de alimentos complementares a gestantes e mães em hospitais e maternidades (ARAÚJO et al., 2006). 
Em substituição, é possível e aconselhável que as instituições de saúde invistam em treinamento e capacitação contínua de sua equipe, em relação às orientações sobre o AME.

Tais orientações devem ser transmitidas para a mulher durante o pré-natal e puerpério, visto que em ambos os países a atuação das equipes de saúde foi decisiva para o início e/ou a manutenção do AME. Isso porque o auxílio à nutriz, em suas dúvidas e dificuldades, possibilita-Ihe praticar o aleitamento com êxito.

Há urgente necessidade de criação de leis que venham a amparar a mulher trabalhadora que amamenta, pois é significativa sua participação no mercado de trabalho em regiões de grande concentração industrial.

Tal afirmação é comprovada quando se observa a média nacional de AME no Brasil, que chega próximo aos $41 \%$ contra apenas $8 \%$, nos EUA. Essa porcentagem reforça o fato de que o mercado de trabalho está marcado por significativas desigualdades de gênero, devendo, assim, ser considerada nos processos de formulação de políticas públicas em geral, pois no Brasil as mulheres representam $43 \%$ da população economicamente ativa, contra $47,3 \%$, nos EUA (LI et al., 2003).

Ainda segundo Li et al. (2003), 60\% dos lactentes norte-americanos são amamentados no período de pós-parto precoce, e apenas $8 \%$ AME por seis meses, o que contraria as recomendações da OMS e da Academia Americana de Pediatria. O período de maior criticidade é, para o DMP, compreendido entre dois e três meses, devido principalmente à necessidade do retorno da mãe às práticas escolares e trabalhistas, assim como à falta de apoio à amamentação nos locais de trabalho.

Com o intuito de manter o AME após o retorno da mãe ao trabalho, recomenda-se que: ela amamente com frequência quando estiver em casa, especialmente à noite, que evite usar mamadeiras e chupetas, oferecendo a alimentação por meio de copo, xícara ou colher, e que pratique a ordenha durante as horas de trabalho (MONTESCHIO; GAIVA; MOREIRA, 2015).

No Brasil, outro fator relacionado ao DMP foi o estado civil da nutriz, assim como o apoio presencial e emocional do parceiro, familiares ou amigos. As mães solteiras mostraram maior dificuldade em manter o AME pelo período preconizado pela OMS. Este foi atribuído à necessidade de retorno ao trabalho precocemente e por se exigir, muitas vezes, que a crian- ça frequente creches ou que fique sob cuidado de familiares ou babás durante seus primeiros seis meses (JOHNSTON; ESPOSITO, 2007).

É importante salientar que o ato de amamentar está muito vinculado ao momento histórico e seus respectivos valores culturais, e a influências familiares e de amigos (JUNGES et al., 2010). As orientações vindas das avós, por exemplo, incluíam principalmente a introdução de chás e água na dieta ainda durante os seis primeiros meses de vida (SUSIN; GIUGLIANI; KRUMMER, 2005).

Tanto no Brasil como nos EUA a influência das avós na prática do AME tem sido descrita na literatura. As avós aconselham as mães a introduzirem água, chás e outros tipos de leite na alimentação das crianças. O convívio com pessoas além do seu círculo familiar torna a criança vulnerável a seguir a alimentação mais conveniente ao cuidador, o que aumenta os riscos de DMP. Em alguns casos essa prática acontece sem o conhecimento da mãe ou autorização dos pais (SUSIN; GIUGLIANI; KRUMMER, 2005).

A influência dos familiares no sucesso ou fracasso do aleitamento materno mostrou-se marcante. Dessa forma, há necessidade de construção de valores sobre a amamentação, junto a nutriz e sua família, valorizando a sua rede de apoio e incluindo-a nos programas de educação em saúde (MONTESCHIO; GAIVA; MOREIRA, 2015).

Sabe-se que a concepção de leite fraco, insuficiente e que não sustenta, decorrente de processos culturais, ocorre principalmente pela falta de conhecimento das mães sobre esses eventos. Tal concepção é consequência da falta de preparo para o aleitamento durante o pré-natal, ou da influência cultural das muIheres da família, ou ainda de experiências frustradas com filhos anteriores.

O estudo de Junges et al. (2010) reconheceu que o respeito aos valores pessoais da mulher buscando solucionar as dúvidas sobre amamentação permite proporcionar uma prática mais saudável e prazerosa, se assim for seu desejo e possibilidade, sem sobrecarregá-la com a cobrança social do "dever materno", Busca-se, assim, combater o sacrifício da mulher em prol do benefício do filho, independentemente de seu sofrimento físico ou emocional.

Nos EUA a intenção da mãe em amamentar e o seu conforto durante a prática têm relação com o período de manutenção da amamentação (JOHNSTON; ESPOSITO, 2007). 
A falta de empenho dos profissionais de saúde em orientar as mães quanto à ordenha e armazenamento do leite materno para que possa ser oferecido ao lactente mesmo durante a ausência da mãe comprometeu o período de AME entre mães brasileiras e norte-americanas (SILVA; SOUZA, 2005).

As Unidades Básicas de Saúde (UBS) e de Estratégia de Saúde da Família (ESF) têm desempenhado papel de destaque no acompanhamento da gestante ou nutriz durante o pré-natal e puerpério, além da pediatria e puericultura para adaptação dos hábitos com orientação principalmente sobre alimentação. Por outro lado, a falta de conhecimento/atualização por parte dos profissionais de saúde teve efeito comprometedor na efetividade das ações das equipes de saúde (JOHNSTON; ESPOSITO, 2007).

Esses profissionais podem influenciar no desmame precoce, por falta de atitude e práticas negativas, assim como por falta de capacitação no manejo adequado do aleitamento. Susin, Gugliani e Krummer (2005) referem e confirmam a recomendação de pediatras para a introdução de complementos, como água, chá e outros alimentos e sua influência no desmame.

Segundo Wolf (2003), para que a campanha de amamentação tenha sucesso deve-se incluir uma equipe capaz de apoiar o processo de amamentação com profissionalismo e persistência, no entanto o treinamento médico norte-americano não inclui capacitação sobre amamentação, tornando as equipes incapazes de orientar de forma apropriada e segura as lactantes.

Enquanto o serviço público brasileiro evoluiu em programas, estratégias e ações que estimulem o AME, nos EUA esse serviço foi responsável pelo aumento das taxas de DMP, uma vez que o governo contribui para a distribuição gratuita de fórmulas lácteas infantis (KRONENFELD, 2017).

Assim, é preciso que os serviços de saúde responsáveis pela disponibilização desses suplementos sejam mais rigorosos em relação à triagem de quem realmente necessita de fórmulas lácteas, como para as mães que não podem amamentar devido ao uso contínuo de medicamentos que impossibilitem o aleitamento.

A intervenção precoce por parte dos profissionais da saúde pode restabelecer uma produção adequada de leite, minimizar a intranquilidade materna e estimular as pessoas mais próximas da família a apoia- rem a nutriz nos momentos de angústias e dúvidas na prática da amamentação (MONTESCHIO; GAIVA; MOREIRA, 2015).

O desconforto, o estresse e a insegurança materna provocados pelas intercorrências mamárias levam à introdução da mamadeira. Tais sintomas reduzem a liberação da ocitocina, prejudicando ainda mais o processo de aleitamento (BRASIL, 2015a).

Por fim, reconhece-se que políticas públicas de incentivo ao aleitamento materno devem ser estimuladas e adotadas pelos governos, incluindo: campanhas na mídia, treinamento de profissionais de saúde, aconselhamentos individualizados, produção de material educativo, estabelecimento de grupos de apoio à amamentação na comunidade, aprovação de leis que protejam a amamentação e que possam controlar o marketing de leites artificiais.

\section{CONCLUSÃO}

Demonstrou-se que, entre os principais fatores que levam ao DMP nos EUA e no Brasil, o retorno da mulher ao trabalho apresentou-se como o mais significativo, e foi possível constatar que o suporte legislativo tem impacto positivo na adesão das mães ao AME.

É marcante, contudo, a influência cultural, principalmente no Brasil, onde persiste a crença de que o leite materno é fraco, ou de que é necessária a introdução de chás na alimentação do bebê antes dos seis meses.

O Brasil oferece maior amparo legal à mulher trabalhadora que amamenta, por meio de leis trabaIhistas que estimulam a prática do aleitamento materno, como licença-maternidade remunerada de quatro meses, incentivando as empresas a estenderem esse prazo para seis meses, por meio de incentivos fiscais e salas de apoio à amamentação. Nos EUA, entretanto, a falta de proteção legal única para todos os Estados força as mulheres ao retorno precoce ao trabalho, o que faz decaírem as taxas de AME.

Em ambos os países a influência dos profissionais da saúde no incentivo ao início e manutenção da amamentação representou fator relevante. Nos EUA, contudo, a falta de treinamento dos profissionais de saúde sobre a importância do AME compromete a prática, colaborando para o DMP. Ademais, o impacto da assistência pública causado nas mães que recebem fórmulas infantis com isenção de custos por meio do programa de nutrição suplementar se apresentou negativa, posto que colabora para o declínio das taxas de AME. 
Assim sendo, o suporte legislativo referente às mulheres em fase de lactação é um tema que merece atenção, por se caracterizar como um fator modificável e de indispensável importância para melhorar o índice do AME, principalmente nos EUA.

\section{REFERÊNCIAS}

AGÊNCIA BRASIL. Pediatras brasileiros criticam investidas dos EUA contra amamentação. Rio de Janeiro, 2018. Disponível em: http://agenciabrasil.ebc.com.br/saude/noticia/2018-07/pediatras-brasileiros-criticam-investida-dos-eua-contra-amamentacao. Acesso em: 18 ago. 2019.

ARAÚJO, M. F. M. et al. Avanços na norma brasileira de comercialização de alimentos para idade infantil. Rev. Saúde Pública, 40(3), p. 513-20, 2006. Disponível em: http://www. scielo.br/pdf/rsp/v40n3/21.pdf. Acesso em: 15 fev. 2017.

BRASIL. Constituição da República Federativa do Brasil: texto constitucional promulgado em 5 de outubro de 1988, com as alterações determinadas pelas Emendas Constitucionais de Revisão nos 1 a 6/94, pelas Emendas Constitucionais nos $1 / 92$ a 91/2016 e pelo Decreto Legislativo no 186/2008. Brasília: Senado Federal; Coordenação de Edições Técnicas, 2016. 496 p. Disponível em: https://www2. senado.leg.br/bdsf/bitstream/handle/id/518231/CF88_Livro_EC91_2016.pdf. Acesso em: 23 abr. 2017.

BRASIL. Presidência da República. Casa Civil. Subchefia para assuntos jurídicos. Lei № 11.770, de 9 de setembro de 2008. Disponível em: http://www.planalto.gov.br/ccivil_03/_ato2007-2010/2008/lei/l11770.htm. Acesso em: 23 abr. 2017.

BRASIL. Caderno de Atenção Básica - saúde da criança: aleitamento materno e alimentação complementar, n. 23. 2. ed. Brasília: Ministério da Saúde, 2015a. Disponível em: http://bvsms.saude.gov.br/bvs/publicacoes/saude_crianca_aleitamento_materno_cab23.pdf. Acesso em: 12 fev. 2017.

BRASIL. Presidência da República. Casa Civil. Subchefia para assuntos jurídicos. Decreto $n$. 8.552, de 3 de novembro de 2015. 2015b. Disponível em: http://www.planalto.gov.br/ ccivil_03/_Ato2015-2018/2015/Decreto/D8552.htm. Acesso em: 12 fev. 2017.

CALIFORNIA. California Paid Family Leave: Helping Californians be Present for the Moments that Matter. DE 2511 Rev., n. 14, 7-17, 2017. Available from: http://www.edd.ca. gov/pdf_pub_ctr/de2511.pdf. Cited: 11 Oct. 2017.

CÂMARA MUNICIPAL DE SÃO PAULO. Justificativa - PL 0417/2016. 2015. Disponível em: http://documentacao.camara.sp.gov.br/iah/fulltext/justificativa/JPL0417-2016.pdf. Acesso em: 23 abr. 2017.

CYRILLO, D. C. et al. Duas décadas da Norma Brasileira de Comercialização de Alimentos para Lactentes: Há motivos para comemorar? Rev. Panam. Salud Publica, 25(2), p. 134140, 2009. Disponível em: https://www.scielosp.org/article/ssm/content/raw/?resource_ssm_path=/media/assets/ rpsp/v25n2/v25n2a06.pdf. Acesso em: 23 mar. 2017.
FIGUEIREDO, S. F. Avaliação da iniciativa Hospital Amigo da Criança na prática do aleitamento materno exclusivo nos primeiros seis meses de vida em uma maternidade pública da cidade de São Paulo. 2009. Dissertação (Mestrado em Enfermagem) - Universidade Federal de São Paulo, São Paulo, 2009. Disponível em: http://repositorio.unifesp.br/ handle/11600/10620. Acesso em: 16 mar. 2017.

GRAZZIOTIN, A. L.; CARVALHO, M. R. Bancos de leite: comparando modelos - EUA x Brasil. 2017. Disponível em: http://www.aleitamento.com/banco-leite/conteudo.asp?$\operatorname{cod}=2303$. Acesso em: 15 ago. 2017.

IBGE. Pesquisa nacional por amostra de domicílios: PNAD. Rio de Janeiro: IBGE, 2011. V. 1.

JOCA, M. T. et al. Fatores que contribuem para o desmame precoce. Esc Anna Nery R Enferm, 9(3), p. 356-364, dez. 2005. Disponível em: http://www.scielo.br/scielo.php?script=sci_arttext\&pid=S14181452005000300004\&lng=pt\&nrm=iso. Acesso em: 11 fev. 2017.

JOHNSTON, M. L.; ESPOSITO, N. Barriers and Facilitators for Breastfeeding Among Working Women in the United States. JOGNN, Journal of Obstetric, Gynecologic \& Neonatal Nursing, 2007. Available from: http://www.jognn.org/article/ S0884-2175(15)33659-5/pdf. Cited: 11 Oct. 2017.

JUNGES, C. F. et al. Percepções de puérperas quanto aos fatores que influenciam o aleitamento materno. Rev. Gaúcha Enferm., Porto Alegre, RS, 31(2): 343-350, jun. 2010. Disponível em: http://www.scielo.br/scielo.php?script=sci_arttext \&pid=S198314472010000200020\&lng=pt\&nrm=iso. Acesso em: 11 fev. 2017.

KOGAN, M. D. et al. Multivariate Analysis of State Variation in Breastfeeding Rates in the United States American. Journal of Public Health, v. I, 98, n. 10, Oct. 2008. Available from: https://www.ncbi.nlm.nih.gov/pmc/articles/PMC2636475/ pdf/1872.pdf. Cited: 11 Oct. 2017.

KEDROWSKI, K. M.; LIPSCOMB, M. E. Breastfeeding Rights in the United States. London, 2008. 175p. ISSN 1558-8734.

KRONENFELD, J. J. Health and Health Care Concerns among Women and Racial and Ethnic Minorities, v. 35, 2017. Available from: https://books.google.com.br/ books? $i d=9$ YUwDwAAQBAJ \&amp;pg=PT43\&amp;lpg=PT43\&amp;dq=Barriers+and+Facilitators+for+Breastfeeding+Among+Working+Women+in+the+United+States\&amp; source=bl\&amp;ots=22Ku0QX32S\&amp;sig=pSDfcbFzM7K3n46PSTCYLDE6F3M\&amp;hl=pt-BR\&amp;sa=X\&amp;ved=0ahUKEwiDkqfY3-jWAhUDOJAKHdXiACkQ6AEIZTAI\#v=onepage\&amp;q\&amp;f=false. Cited: 11 Oct. 2017.

LI, R. et al. Prevalence of Breastfeeding in the United States: The 2001 National Immunization Survey. Pediatrics, Illinois, v. 111, n. 5, May 2003. Available from: http://pediatrics.aappublications.org/content/pediatrics/111/Supplement_1/1198.full.pdf. Cited: 11 out. 2017.

MARGOTTI, E.; MARGOTTI, W. Fatores relacionados ao aleitamento materno exclusivo em bebês nascidos em Hospital Amigo da Criança em uma capital do Norte brasileiro. Saúde Debate, Rio de Janeiro, v. 41, n. 114, p. 860-871, jul./set. 2017. Disponível em: https://scielosp.org/pdf/sdeb/2017. v41n114/860-871/pt. Acesso em: 11 set. 2017. 
MONTESCHIO, C. A. C.; GAIVA, M. A. M.; MOREIRA, M. D. S. O enfermeiro frente ao desmame precoce na consulta de enfermagem à criança. Rev. Bras. Enferm., 68(5): p. 587-593, 2015. DOI: http://dx.doi.org/10.1590/00347167.2015680515. Disponível em: http://www.scielo.br/ pdf/reben/v68n5/0034-7167-reben-68-05-0869.pdf. Acesso em: 28 mar. 2017.

OLIVEIRA, C. S. et al. Amamentação e as intercorrências que contribuem para o desmame precoce. Revista Gaúcha de Enfermagem, Porto Alegre, RS, 36(esp), p. 16-23, 2015. Disponível em: http://www.scielo.br/scielo.php?script=sci_ arttext\&pid=S19814472015000500016\&lng=pt\&nrm=iso. Acesso em: 11 fev. 2017.

PASTORAL DA CRIANÇA. Amamentação: um ganho para toda vida! 2017. Disponível em: https://www.pastoraldacrianca.org.br/amamentacao/amamentacao-um-ganho-para-toda-vida\#meta-superada. Acesso em: 11 fev. 2017.

REDE INTERNACIONAL EM DEFESA DO DIREITO DE AMAMENTAR (IBFAN). Quem somos. Jundiaí, 2008. Disponível em: http://www.ibfan.org.br/site/. Acesso em: 3 fev. 2017.

ROCCI, E.; FERNANDES, R. A. Q. Dificuldades no aleitamento materno e influência no desmame precoce. Rev. Bras. Enferm., 67(1), p. 22-27, jan./fev. 2014. Disponível em: http:// www.redalyc.org/articulo.oa? $\mathrm{id}=267030130003$. Acesso em: 18 mar. 2017.

SILVA, A. P.; SOUZA, N. Prevalência do aleitamento materno. Rev. Nutr., Campinas, 18(3), p. 301-310, maio/jun. 2005. Disponível em: http://www.scielo.br/scielo.php?script=sci arttext\&pid=S141552732005000300002\&lng=pt\&nrm=iso. Acesso em: 11 mar. 2017.

SUSIN, L. R. O.; GIUGLIANI, E. R. J.; KRUMMER, S. C. Influência das avós na prática do aleitamento materno. Rev. Saúde Pública, 39(2), p. 141-147, 2005. Disponível em: http://www.scielo.br/scielo.php?script=sci_arttext\&pi$\mathrm{d}=$ S003489102005000200001\&lng=pt\&nrm=iso. Acesso em: 13 abr. 2017.

TOMA, T. S.; REA, M. F. Amamentação e a saúde da mulher e da criança. Cad. Saúde Pública, Rio de Janeiro, 24 Sup 2:S235-S246, 2008. Disponível em: http://www.ibfan.org. br/documentos/outras/doc-332.pdf. Acesso em: 23 mar. 2017.
UNITED NATIONS. The world's women: trends and statistics. New York; 2010. Available from: unstats.un.org/unsd/publication/SeriesK/SeriesK_19e.pdf. Cited: 10 set. 2017.

UNITED STATES. Breastfeeding Report. Card. CDC, 2014. Available from: https://www.cdc.gov/breastfeeding/pdf/ 2014breastfeedingreportcard.pdf. Cited: 11 out. 2017.

VICTORA, C. G. et al. Associação entre aleitamento materno e inteligência, escolaridade e renda aos 30 anos: estudo prospectivo de coorte de nascimentos no Brasil. Lancet, v. 3, n. 4, p. 199-205, abr. 2015. Disponível em: https://www.thelancet.com/journals/langlo/article/PIIS2214-109X(15)70002-1/fulltext. Acesso em: 19 ago. 2019.

WOLF, J. H. Low Breasteeding Rates and Public Health in the United States. American Journal of Public Health, v. 93, n. 12, Dec. 2003. Available from: http://ajph.aphapublications.org/doi/pdf/10.2105/AJPH.93.12.2000. Cited: 11 out. 2017.

WORLD BANK. World development indicators online. Washington, DC: World Bank. 2012. Available from: http://data. worldbank.org/data-catalog/world-development-indicatorshttp://data.worldbank.org/data-catalog/world-development-indicators. Cited: 20 mar. 2017.

WHO. World Health Organization. Collaborative Study Team on the Roleof Breastfeeding on the Prevention of Infant Mortality. Effect of breastfeeding on infant and child mortality due to infectious diseases in less developed countries: a pooled analysis. 2009. Available from: https://www.thelancet.com/pdfs/journals/lancet/PIIS0140-6736(00)820115.pdf?code=lancet-site. Cited: 15 mar. 2017. 